\title{
Estudo comparativo das inclusões do alastrim e da variola vera*
}

\author{
pelos \\ Drs. C. Magarinos Torres e J. de Castro Teixeira
}

( Com 7 estampas)

O presente trabalho é baseado no estudo de biopsias praticadas em oito casos de alastrim desde o segundo até o setimo 'dias de erupção' e no de uma biopsia de variola (variola vera).

Tivemos em vista comparar e documentar, na maior escala possivel, com desenhos e photographias, as alterações cellulares especificas encontradas em material das duas affecções acima referidas, cujas relações reciprocas constituem problema nosologico, a nosso vêr. ainda não resolvido de modo concludiente.

Como alterações cellulares especificas comprehendemos aquellas que occorrem nas doenças produzidas por ultravirus, ora no cytoplasima, ora no nucleo, ora em ambas essas estructuras, e que apresentam aspecto peculiar e caracteristico para cada uma dellas. A primeira condição é, assim, a de não se enquadrarem no typos de idegenerescencias, infiltrações, necrobiose e necrose associados commummente a lesões toxicas e circulatorias. Tambem não levaremos em conta formações outras acaso existentes no cytoplasma das cellulas epidermicas, taes como leucocytos phagocytados, nucleolos em exlrusão, ou chromatina emigrada para o cytoplasma.

É facto bem conhecido que as alterações especificas das doenças por ultravirus referidas como «inclusões", apresentam grande variabilidade de aspecto em um mesmo virus, ainda quando examinadas em cellulas de um mesmo tecido e em animaes da mesma especie. É para notar, porém, que ao lado de aspectos pouco caracteristicos, geralmente relacionados ou com estadios iniciaes, ou, ao contrario, com phases muito adiantadas do processo, é sempre possivel, para cada virus, evidenciar aspectos typicos das inclusões. Taes aspectos typicos são inconfundiveis com outros acaso encontrados nesse mesmo tecido ou alhures e relacionados com virus de outra natureza.

\footnotetext{
* Recebido para publicação a 30 de Novembro de 1934.
} 
Em outras palavras, os estudos morphologicos recentes tendem a estabelecer, que, para cada doença por ultravirus com inclusões especificas, existe um aspecto typico da inclusão, inconfundivel com o que mostram outras doenças do mesmo grupo. Varia, conforme a affecção, $o$ tecido e o animal onde se encontram as inclusões typicas (systema nervoso central do cão na raiva, cellulas epidermicas do homem na variola vera e no alastrim, cellula hepatica do Macacus rhesus na febre amarella, etc.).

Varias vezes taes aspectos typicos têm sido aproveitados em estudos comparativos nesse grupo de doenças (Cowdry e Kitchen, 1930).

No caso especial das inclusões cytoplasmaticas da variola, ha ainda a considerar a possibilidade de algumas dellas, as incluidas por Paschen (1934) no grupo 5 ( «kappenartig dem Kerne aufsitzende Gebilde, ähnlich wie bei Verruga peruviana»), representarem colonias do proprio agente da molestia. Terão essas inclusões constituidas por "colonias do agente", aspecto identico na variola e no alastrim?

A origem das "inclusões》 ou melhor as suas relações com os componentes normaes da cellula e com o agente etiologico, constituem questão morphologica das mais arduas. O seu estudo necessita, naturalmente, o emprego de todos os recursos de investigação biologica (methodos para demonstração das diversas organellas cellulares: nucleo, nucleolo, cytoplasma, centro cellular, chondrioma, apparelho de Golgi, vacuoma, e, tambem, a coloração vital, supravital, a micro-incineração, micro-fluoroscopia e a observação a fresco, além de technica adequada á evidenciação do agente etiologico).

Comtudo, se se tem em vista, simplesmente, a evidenciação das "inclusões das doenças por ultravirus», a technica poderá ser das mais simples, a maioria dellas sendo de prompta caracterisação em tecidos fixados no Zenker, incluidos em paraffina, corádos os córtes pelos methodos rotineiros de technica histologica.

\section{HISTORICO}

Não é acceita, actualmente, pela maioria dos autores,, a opinião de Ribas (1910) e outros, segundo a qual o alastrim seria uma doença diversa da variola.

Ao contrario, apezar de alguns dados discordantes (Plehn, 1925, Nag., 1929), a opinião das maiores autoridades sobre o assumpto (Gins, 1927, Kaiser, 1934) são a favor de considerar o alastrim simples modalidade attenuada da variola vera. Tal identificação é principalmente baseada em provas serologicas, quer leitas em doentes, quer em animaes com infeç̧ão experinental (Ledingham, 1925) e em dados epidemiologicos. A possibilidade da concomitancia do alastrim e da variola em uma mesma região, conforme suggere 
Plehn (1925), a possibilidade de virus proximos determinarem na cornea do coelho inclusões cellulares parecidas e apresentarem reacções de immunidade communs, são criticas cabiveis á maioria dos referidos trabalhos, justificando a opinião que considera a questão como ainda não resolvida de modo concludente (Jorge, 1924).

Visando este trabalho o estudo comparativo entre as alterações cellulares especificas do alastrim e as da variola vera, será util um rapido resumo das contribuições anteriores mais importantes a esse respeito

Descriptas primeiramente por Guarnieri (1892) nas lesð̃es da pelle e mucosas de doentes de variola, e depois na cornea do coelho inoculado com' variola e com vaccina, os curpusculos de: Guarnieri são, em seguida, citados em numerosas publicações relacionadas com a etiologia, a anatomia pathologica e o diagnostico da variola e da vaccina. Comtudo, conforme assignala Hammerschmidt (1919), as suas descripções nas lesões da variola humana são assaz escassas, o que contrasta com a rica documentação a seu r espeito quando na cornea do coelho.

O nome de "corpusculo de Guarnieri " attribuido, quer ás inclusões cytoplasmaticas da variola, quer ás da vaccina, traduz a opinião segundo a qual as inclusões seriam perfeitamente identicas nos dois casos. Aliás é commum encontrar, na literatura actual, expressões taes como "o virus, ou, o agente da variola-vaccina", traduzindo a ideia theorica da identidade dos dois virus. Recentemente, no entanto, o estudo comparalivo das inclusões cytoplasmaticas veio mostrar que ellas não eram identicas no caso dos virus do alastrim e da vaccina (Torres e Teixeira, 1934a).

Segundo Paschen (1911), os corpusculos de Guarnieri teriam sido vistos anteriormente por van der Loeff (1886) e por L. Pfeiffer (1887) na conteúdo de pustulas variolicas. Tambem Weigert (1874) teria visto essas inclusões cellulares, a julgar pela seguinte e curta referencia enconlrada em seu trabalho: "viele Zellen zeigen dunkle Körner neben dem Kerne; eine Art Knospe".

Noç̃̃es desenvolvidas sobre a histologia da variola são encontradas nos trabalhos de Weigert $(1874,1875$ e. 1877), embora outros pesquizadores (Rayer, 1835, Cornil, 1866, Auspitz, 1867, etc.) o tenham precedido. Apror veilando material colhido em 200 cadaveres de variola durante a grande epidemia de Breslau em 1871 e 72, estuda o aspecto histologico da efflorescencia em seus diversos estadios. Na phase precoce, a alteração principal consta de uma degenerescencia peculiar das cellulas da camada profunda da rete Malpighi (degenerescencia diphteroide), acompanhada de desapparição dos nucleos e morte das cellulas. O processo degenerativo seria semelhante ao que Wagner descrevera na diphteri.a "Die diphteroide Degeneration ist nicht nur die erste, sondern sie ist auch die einzige, direkte und besondere Wirkung, die man dem Pockengifte für die Epidermis zuzuschreiben braucht" (Weigert, pg. 18). A efflorescencia origina-se não só na epiderme, como na visinhança de glandulas e folliculos pilo-sebaceos.

Comtudo, as primeiras referencias feitas, de modo indubitavel, ás alterações cellulares especificas da variola, são encontradas no trabalho de Guarnieri (1892). São descripções notaveis para a epoca em que foram realisadas, e tambem, as que melhor reșumem os caracteres essenciaes das inclusóes dytoplasmaticas da variola. "J'ai commencé par l'étude des altérations va- 
rioleuses de la peau et des muqueuses chez l'homme» (Guarnicri, pg. 195). "Dans la portion du protoplasma plus proche du noyau se trouvent, comme creusés, des espaces clairs qui, quelquefois, atteignent la grandeur de presque les deux tiers de la cellule. Dans ces vides, complètement transparents ou remplis d'un détrictus finement granuleux, est contenu le noyau, lequel eš́, ordinairement. repoussé d'un côté. Outre le noyau, on y trouve constammien! des corpuscules qui se colorent fortement avec le carmin boracique, avec l'hematoxyline, avec la safranine, avec le rouge de Maigenta, etc. Ils son de forme diverse, avec saillies irrégulières arrondies. Ils ont un volume très différent. Quelquefois ils attejgnent la grandeur de presque la moitié d'un noyau épithélial; d'autres fois ils sont très petit's et comparables à un micior aoccus" (Guarnieri, pg. 196). "Les cellules épithéliales superficielles, celles qui se trouvent immédiatement au-dessous du stratum lucidum, sont gonflées et, en se comprimant les unes les autres, prennent l'aspect de cellules végétales à l'interieur desquelles on voit quelquefois le corpuscule nettement distinct du noyau» (Guarnieri pg. 198).

Em tres cadaveres de variolosos, Guarnicri encontrou os corpusculos não só na pelle, como nas mucosas do larynge e do pharynge. Obteve pustulas na mucosa dos labios de coelhos inoculados com vaccina e descreve as inclusões na cornea do coelho. Refere o aspecto vacuolado dos corpusculos da vaccina, observando que os estadios mais avançados dos corpusculos na cornea do coelho se encontram junto aos pontos de inoculação, ao passo que corpusculos menores apparecem em zonas mais distantes. Observa, ainda, os corpusculos da vaccina a fresco, colorindo-os pelo azul de methyleno.

Unna (1894) distingue nas lesões da variola dois typos de degenerescencia. A "retikulierende Degeneration" interessa as cellulas das camadas superficial e media do corpo mucoso, caracterisando-se peia apparição de multiplos vacuolos em cada cellula, separados por delgados septos de protoplasma. Esse processo conduz á formação de vesiculas. A «ballonierende Dego neration" compromelte, de preferencia, as cellulas epidermicas jovens, ou seja, as da camada basal e immediatamente adjacentes, traduzindo-se por homogenisação do plasma e arredondamento da cellula que perde as connexões que normalmente apresenta com os elementos contiguos. Assignala na variola, a raridade de cellulas epitheliaes gigantes multinucleadas, tão abundantes, no emtanto, na varicella.

Hückel (1898) publica a mais detalhada documentação até hojé encontrada na litteratura sobre as inclusões cytoplasmalicas da vaccina na cornea do coelho. São 178 figuras, a maioria coloridas pela miștura de Biondi, distribuidas em 4 estampas lithographadas. Os resultados a que cliegou, em suas linhas principaes, conservam-se, ainda hoje, de pé, embora na occasião, discordassem inteiramente das doutrinas acceitas. "Allein in dieser Richtung haben meine Untersuchungen als positives Resultat ergeben, dass bei Vaccine an der Impfstelle in der Cornea zunächst gewisse Theile des Zelleibs del Epithelien, die der Markschicht des Protoplasmas angehören, in ganz eigenartiger Weise erkranken. Die hierbei entstehenden eigenthümlichen Bildungen, deren mannigfache Gestalten durch wechselnde und noch unbekannte Strukturverhältnisse des Cytoplasmas bedingt sein müssen, erscheinen danach als direkte Abkömmlinge des letzteren und nicht als die ursächlichen parasitäre Protozoen der Vaccine, für welche sie ausgegeben worden sind (Hückel, pg. 130). 
No trabalho de Gorini (1901) encontram-se bons desenhos illustranda a particularidade das inclusões cytoplasmaticas da vaccina recalcarem o nucleo, deformando-o.

Councilimann, Margrath e Brinckeerhoff (1904), aproveitando material colhido em 54 necropsias, estudam detalhadamente a anatomia pathologica da variola. As descripções das alterações cellulares especificas são gı'andemente prejudicadas pela doutrina que acceitam de sua natureza parasitaria. Comtudo a rica documentação encontrada nesse trabalho, não só sobre as inclusões cytoplasmaticas, como sobre as que hoje são chamadas "inclusões intranucleares» (Plate IX e XII, Figs. 4, 7, 8 i 9), é sufficiente para garantir-lhe um logar proeminente na litteralura.

Ewing (1904) chama a attenção para a variabilidade das reacções de coloração das inclusões cytoplasmaticas da variola, embora sejam, ordinariamente, acidophilas. Mostram ellas uma estructura nitidamente reticulada, sendo que o reticulo que encerram apresenta confinuidade com o cytoreticulo. As inclusões intranucleares foram vistas em 17, dentre 24 casos estudados. Dos sete casos que não as mostravam, dois tinham lesões extensamente supnur radas nas quaes era impossivel reconhecer cellulas epitheliaes, tres eram casos com lesões hemorrhagicas primarias e raras inclusões cytoplasmaticas. Finalmente, dois eram casos de variola hemorrhagica confluente. Assignala que as inclusões intranucleares existem unicamente em cellulas em via de necrose. Em um córte histologico de pustula, ellas começam a apparecer bruscamente quando se passa da zona de cellulas com inclusões cytoplasmaticas e degenerescencia hydropica para a de cellulas necrosadas que formam a base da pustula.

As estampas encontradas no trabalho de Bosc (1904) evidenciam a safraninophilia accentuada das inclusões da vaccina.

Tyzzer (1906) refere o encontro de inclusס̃es cytoplasmaticas triangular res, representadas na figura 84 do trabalho de Hükel, em corneas de coelho não inoculadas. As figuras coloridas da sua "Plate XXVI " são uma bôa illustração das diversas phases evolutivas dos corpusculos de Guarnieri, nellas se destacando a representação de uma zona clara vacuolada ou rarefeita no cytoplasma, evidentemente relacionada com as inclusões (v. figuras 1 a 9 e 16 a 20).

Brinckerhoff e Tyzzer (1906) verificam que as alteraçóes nucleares, provavelmente as que hoje conhecemos sob o nome de "inclusões intranucleares", occorrem apenas em cellulas epitheliaes nos animaes inoculados com o virus da variola $e$ não nos inoculados com o 1 da vaccina. Em material proveniente de diversas especies de macacos (Macacus cynomol gus, Macacus nemestrinus, Simia satyrus) com variola experimental e com vaccina, assignalam "cytoplasmic forms of Cytoryctes" em cellulas do epithelio pavimentoso da pelle, da cornea, da bocca e do esophago, em cellulas das glandulas sebaceas e de Meibom, no epithelio cylindrico do nariz, da tralchea, da vesicula seminal, no epithelio dos alveolos pulmonares, nas cellulas endotheliaes e cellulas do tecido conjunctivo.

Keyssilitz e Mayer (1909), autopsiando um negro de 30 annos, morto de variola no inicio do exanthema (entre o quinto e o sexto dia de molestia) encontraram, no figado e nos pulmões, lesões semelhantes ás da pelle. As inclusões intranucleares eram muito numerosas nas cellulas hepaticas (Taf. I, 
Figs. 23, 25, 26, 27 e 38), existindo, por vezes, juntamente com inclusóes cytoplasmaticas (Taf. I, Fig. 38). Eram vistas, tambem, no baço, no endothelio dos vasos sanguineos e em cellulas da adventicia. Corpusculos de Guarnieri foram encontrados no epithelio renal.

No trabalho de Unna (1910) são encontradas bôas illustrações das lesões da variola (Taf. XXIV e XXV).

Hallenberger (1918) estuda os corpusculos de Guarnieri em casos de variola e na cornea do coelho, tanto em esfregaços, como em córtes histologicós corados pelo Giemsa. Occupa-se, tambem, com as relaçóes existentes entre os corpusculos de Paschen ("initial Körperchen» de Prowazek) e os corpusculos de Guarnieri. Esses ultimos são considerados como productos de reacção do cytoplasma, nada tendo a ver com o virus da variola. Considera o esparao ovoide, claro, observado em torno de quasi todas as inclusões como artificio produzido pela retracção daquellas estructuras. Affirma que os corpusculos de Guarnieri são escassos e rudimentares nas pustulas da variola, só excepcionalmente ahi mostrando os seus dois componentes: a chromatina e o manto de plastina.

Hammerschmidt (1919) admitte a origem nucleolar dos corpusculos de Guarnieri baseado na semelhança de coloração dessas duas estructuras em preparações corádas pelos methodos de Unna pelo hemalaun-safranina e pelo verde de methyla-pyronina. A safraninophilia das inclusões cytoplasmaticas é observada, egualmente, na cornea do coelho inoculada com vaccina e com o virus da variola. A multiplicidade das inclusões cytoplasmaticas da variola (matcrial de vesicula do homem!) é evidenciada na figura 3 do seu trabalho. Resume as opiniões sobre o vacuolo que circumda os corpusculos de Guarnieri: "Schon Bosc war der Ansicht, dass es sich dabei nicht um einen Hohlraum, sondern um eine homogene, stark lichtbrechende Substanz handeln dürfte. die sich schwer färbt und die Aufgabe hat, ähnlich wie die Kapseln der Bakterien, den Parasiten zu schützen und eventuell für die Umwandlung der notwendigen Stoffe Sorge zu tragen. Da, wie später auseinandergesetzt wird. der Nukleolus als ein wichtiges Sekretionsorgan fungiert, muss man wohl daran denken, dass der Hof vielleicht mit dieser lebhaften Sekretion in Bezichung stehen könnte" (Hammerschmidt, pgs. 70 e 71). Considera, ainda, como questão duvidosa, a presença de inclusões nucleares na variola.

Boing (1920) colorindo pelo Azur l, esfregaços e córtes de cornea de coelho inoculada com vaccina, verifica, quer nos corpusculos de Guarnieri, quer no nucleo das cellulas epitheliaes da cormea, pequenissimas granuləçães vermelhas, que se destacam com nitidez no fundo azul de plastina, e que corresponderiam a chlamydozoarios. "Auf Grund weiterer vergleichender Untersuchungen mit Originalpräparaten von Herrn Paschen glaube ich, dass die von Paschen als Erreger ausgesprochenen Körnchen sich decken mit meinem Körnchenbefund in den Guarnierischen Körperchen und in den Kernen " (Boïng, pg. 624).

Cowdry (1922), a proposito das zonas claras de cytoplasma que circumdam as inclusores, diz: "The fact that they are not visible in the case of vaccine bodies supravitally stained with brillant cresyl blue is not very helpful because neither do I find the bacterial halos in insect material. Nevertheless, it can hardly be denied that their appearance is strongly suggestive of shrinkage at interfaces between fluids of different consistency and com- 
position" (Cowdry, pg. 676). Nas conclusões, diz: "Vaccine bodies in living corneal cells may be specifically stained by the addition of a small quantity of brilliant cresyl blue $2 \mathrm{~B}$ to the physiological salt solution in which they are being observed. Their appearance by this method (Figs. 3 to 17) corresponds with that seen in fixed preparations (Figs. 22 to 42). Both lines of study reveal the existence of traces of similar material in unvaccinated corneal cells. As this increases in amount during the reaction, it behaves like an integral, cytoplasmic constituent of fluid consistency and shows no evidence of being endowed with any measure of independent vitality " (Cowdry, pg. $680)$.

Gins (1922) notando a difficuldade por vezes encontrada na pesquiza dos corpusculos de Guarnieri na cornea do coelho, procura descobrir outras alterações cellulares especificas evidenciando cellulas que elle denomina "Strahlzellen". "Man kann sich das Verhalten des Virus im Hornhautepithel dem nach folgendermassen vorstellen: 1. Eindringen des Virus in die Epithelzelle und Einwanderung in den Zellkern. Die von v. Prowazek gefundenen Initialkörperchen stellen vielleicht das auf der Wanderung durch das Protoplasma befindliche Virus dar. 2. Entwicklung des Virus im Kern zu einer dichten Masse grösserer Körperchen, die den ganzen Kern ausfüllen. 3. Heraustreten dieser Körperchen, aus dem Kern, weiteres Wachstum in der allmählich verschwindenden Epithelzelle ("Strahlzelle»), Auswanderung zwischen die Epithelien (extrazelluläre Form der Variola-Vaccinekörperchen). 4. Eindringen der Körperchen in das Protoplasma der Epithelzellen (typisches Guarnierikörperchen). 5. Reifung innerhalb der Zelle und Zerfall der Elementarkörperchen (Paschensche Körperchen), die dann in grossen Massen aus den zorstörten Epithelzellen austreten oder, 6. allmähliche Resorption in der nicht durch den Parasiten zerstörten Zelle» (Gins, pg. 276).

Borrel e Mlle. Muller (1924) e Borrel (1925) descrevem na cornea do coelho inoculada com virus vaccinal, retirada no fim de $24-28$ loras, etc. e conservada na camara humida a 30o durante 4, 6, 12, 24, 48 horas, etc. corpusculos apparentemente identicos aos que eram anteriormente designados como "corpusculos de Paschen". Estabelece ainda que os corpusculos de Guarnieri, muito abundantes nesse material, são formados por taes elementos cujas dimensões não excedem de $0,1 \mu$. "Par le Giemsa on obtient des préparations montrant le mode de formation des corps de Guarnieri, cerlaines cellules vaccinales contiennenít 30 el 10 corpuscules réticulés amoebiformes avec un grain central, à la limite de la visibilité, par une véritable processus de coalescence, il se constitue ensuite un gros corps central unique qui représente le corps de Guarnieri bien connu» (Borrel, 1925).

Sörensen e Sörensen (1925) aproveitando material colhido em oito necropsias de variola, assignalam dois aspectos diversos dos corpusculos de Guarnieri. Quando observados nas cellulas epitheliaes superficiaes do corpo mucoso, apresentam-se como granulos de tamanho variavel, tintos em azul ou violeta (preparados pelo Giemsa e pelo violeta de gentiana) ora circumdando o nucleo á maneira de uma corôa, ora occupando um ou os dois polos do nucleo. Nas cellulas epidermicas das camadas profundas e nas do epithelio das glandulas sudoriparas e folliculos pilo-sebaceos são inclusões de fórma sempre redonda ou oval, de tamanho variavel, em regra circumdadas por um vacuolo claro, de côr vermelha ou avermelhada. Em todos os casos hu- 
manos, os corpusculos de Guarnieri existiam em quantidade variavel e com predilecção nas "ballonierten Retezellen".

Schütz (1926) estuda os corpusculos de Guarnieri na cornea de coelhos empregados na reacção de Paul, fixadas pelo Champy e Kopsch, corados pelo кull. Unna. Biondi e hematoxylina ferrica. Nos estadios iniciaes, os corpusculos são multiplos, mais tarde, apparecendo isolados ou aos pares. Menciona a sua localisação juxtanuclear e a propriedade que tèm de deprimir o nucleo, ahi se alojando. Confirma a verificação de Cowdry', segundo a qual as mitochondrias e o apparelho de Golgi não dão origem aos corpusculos de Guarnieri, considerando destituidas de fundamento as hypotheses sobre a origem nuclear dos corpusculos de Guarnieri. "So kommen wir zu dem Schluss, dass die G. K. cytoplasmatische Gebilde sui generis sind, die aus winzigen sph roidalen Körperchen (Tröpfchen) hervorgehen und $\mathrm{zu}$ keinen normalen Zellorganellen in genetischer Beziehung stehen» (Schütz, pg. 9). A sua experiencia é contraria á existencia das "Strahlzellen» de Gins. Considera a vacuolisação dos espermatocytos, embrora sem a presença de inclusões, como lesão muito typica nos testiculos injectados com vaccina.

Luger e Lauda (1926) distinguem dois aspectos nas alterações intranucleares da variola. "Es findet sich eine Gruppe, bei welcher ein ausserordentlich scharf umschriebener und daher korpuskulär erscheinender rundlicher oder ovaler Körper von verschiedener Grōsse, der schliesslich den ganzen Kern ausfullen kann, auftritt, der eine ziemlich ausgesprochene Oxyphilie aufweist und dadurch charakterisi rt erscheint, dass er sehr häufig, wenn auch nicht regelmässig, eine sich schliesslich auf das ganze Gebilde erstreckende Vakuolisierung erkennen lässt, die dem Gebilde einen wabenartigen Charakter verleiht" (Luger e Lauda, pg. 417). "Eine andere Gruppe von Kernveländerungen entspricht jedoch durchaus, wie die Abb. 4 und 5 zeigen, den bei den Varizellen bzw. den Herpesarten geschilderten Formen. Sie unterscheiden sich von der ersten Gruppe dadurch, dass es sich hier nicht um scharf umschriebene körperliche Gebilde handelt, dass vielmehr hier eine teils homogene, teils krümelige, teils feingekörnte Masse nachzuweisen ist, die entweder den Kern vollständig ausfüllt oder auch von der Kernmembran durch einen anscheinend optisch leeren Spaltraum getrennt ist".

Findlay e Ludford (1926) resumem os principaes trabalhos a respeito das inclusões da variola e da vaccina. Adoptando o criterio de excluir as figuras sem detalhes cytologicos claros $\mathrm{e}$ as que illustram factos bem conhecidos, elles reproduzem 61 figuras retiradas dos trabalhos de Guarnieri, Copeman e Mann, Ewing, Boïng, Cowdry e Schütz.

Michelson e Ikeda (1927), aproveitando material colhido em 47 necropsias e duas biopsias de variola, descrevem as alterações histologicas encontradas desde a pn̉ase inicial de formação de vesicula até a de cicatrização. A referencia mais extensa ás inclusões é assim enunciada: "They (the inclusion bodies) $^{1}$ varied decidedly in number but were of uniform size. They were perfectly round, coloured deep blue with hematoxylin and were found most often in the middle epithelial layers within the cells in the vicinity of the nucleus». Nenhuma referencia é feita ás inclusões intranucleares.

1 O grypho è nosso. 
Kyrle (1927) descreve c illustra diversos estadios evolutivos do exanthema da variola, insistindo sobre analogias histologicas entre variola e outras doenças eruptivas, especialmente o herpes zoster.

Ludford (1928) chega á conclusão de que as inclusões produzidas pelo virus da vaccina nas cellulas epidermicas da pelle e na cornea da gallinha são identicas ás do epithelioma das aves. Os corpusculos da vaccina apresentariam relações com o apparelho de Golgi e os corpusculos de Guarnieri seriam de origem nucleolar.

Claríce (1928) é um dos ultimos a defender a natureza parasitaria das inclusões da variola e da vaccina. identificando-as a um protozoario.

River, Haagen e Muckenfuss (1929), cultivando in vitro corneas de coelho inoculadas com vaccina, obtêm, além de corpusculos de Guarnieri, "basophilic structures that were considered to be Paschen bodies .

Nauck e Paschen (1932) dizem que os corpusculos de Guarnieri são productos de reacção da cellula á acção do virus ou de suas toxinas. Só um pequeno numero delles é formado por colonias do agente ("Erregerkolonien"), a maioria sendo de origem toxica e produzidos por uma dissociação de particulas de plastina e de chromatina existentes na cellula normal.

Paschen (1932) acha que os corpusculos de Guarnieri podem ser constituidos por cinco materias differentes, a saber: 1. leucocytos phagocytados. 2. nucleolos emigrados para o plasma. 3. particulas de chromatina destacadas no nucleo e localisadas no plasma adjacente. 4. porções de plastina e de chromatina presentes no cytoplasma e dissociadas pela acção de uma toxina. 5. estructuras que recobrem o nucleo tal como acontece na Verruga peruiviana. Os corpusculos incluidos nos grupos 4 e 5 seriam os unicos pathognomonicos, sendo que apenas os do grupo 5 encerrariam o agente ("corpusculos de Paschen ").

Milovidow (1933) verifica que os corpusculos de Guarnieri obtidos na cornea do coelho inoculada com "Variolavakzine" apresentam uma reacção de Feulgen positiva, contendo, assim, acido thymonucleinico. Os corpusculos de Guarnieri representariam restos de leucocytos phagocytados pelas cellulas epitheliaes. Illustra inclusões juxta-nucleares que deformam o nucleo, simulando uma rede intranuclear.

Embora apresentem os corpusculos de Paschen estreitas relações com os de Guarnieri, dispensamo-nos de relatar o seu historico, que se encontra bem resumido no trabalho de Paschen (1911, pg. 510).

Corpusculos semelhantes aos de Paschen foram evidenciados, pela primeira vez, no alastrim por Aragão (1911 e 1933).

Mitamura, Tamiya, Hazato, Ichinomiya e Fujivara (1934) chegam á conclusão de que os corpusculos de Guarnieri e os de Paschen representam formas coradas differentes do agente da variola-vaccina. "Unserer Ansicht nach stellen die Guarnierischen Körperchen das erste Stadium, und die Paschenschen Körperchen das zweite Stadium des Errregers dar, etwa wie die Vegetation und Dauerformen der Bakterien oder der Pilze» (pg. 377). Os aucto res encontram, na variola das aves, formações semelhantes aos corpusculos de Guarnieri, precedendo, de um a dois dias, a apparição dos corpusculos de Böllinger. 


\section{MATERIAL}

Consta elle de biopsias de pelle praticadas em 8 doentes de alastrim durante uma epidemia occorrida em 1932. em tropa aquartelada na cidade Rio de Janeiro, Brasil.

O mascrial de variola vera consta de uma biopsia praticada durante a grande epidemia ${ }^{2}$ observada $\mathrm{em} 1926$, na população civil da cidade do Rio de Janeiro, Brasil.

Os fragmentos de pelle com as lesões de alastrim seleccionadas eram, immediatamente, fixados em liquido de Zenker contendo $10 \%$ de formol do commercio. Lavagem $\mathrm{em}$ agua corrente, 24 horas. Com uma lamina de navalha Gillette, as lesões eram dividads em 2 ou mais blócos, ora no sentido do seu maior diametro, ora no do menor. Deshydratação em alcool absoluto mudado 3 vezes, de 2 em 2 horas. Chloroformio durante uma noite (usado um tampão de algodão para manter submergidos os fragmentos). Chloroformio préviamente aquecido a 57\%, 15 minutos. Juntar partes eguaes de paraffina fundida ao recipiente contendo as peças no chloroformio, prolongando o banho durante 1-2 horas. Banho de paraffina pura, 2 horas. Inclusão em paraffina.

Como corantes, usamos o methodo rotineiro pela hematoxylinaeosina e o methodo de Unna pelo hemalaum-safranina modificado, feito do seguinte modo:

Córtes desparaffinados e hydratados são corados pela hematoxylina de Delafield diluida durante 10 minutos. Lavagem em agua da bica, 10 minutos. Solução aquosa de safranina a $1 \%, 10$ minutos. Agua. Solução aquosa de tanino a $25 \%, 10$ minutos. Agua. Alcool. Oleo de bergamota-xylol. Xylol. Balsamo.

A excellencia deste methodo no estudo das inclusões desse grupo de doenças foi assignalada por Hammerschmidt (1919) e por Paul (1919). Conforme referimos anteriormente (Torres e Teixeira, $1934 \mathrm{~b}$ ), permitte elle fazer o diagnostico differencial entre as inclusões cytoplasmaticas do alastrim e as da variola vera, e tambem entre as do alastrim $\mathrm{e}$ as da yaccina nas lesões cutaneas experimientaes do $\mathrm{Ma}$ cacus rhesus: por esse methodo de coloração, as inclusões cytoplasmaticas do alastrim, no homem e no macaco, não se coram pela safrał nina, ao passo que as da variola vera e as da vaccina apresentam umà accentuada safraninophilia.

\footnotetext{
2 Segundo dados colhidos no Boletim Mensal de Estatistica Demographo-Sanitaria da Cidade do Rio de Janeiro, foram feitas, então, 4.146 notificações de variola, o numero de obitos por essa molestia registrado sendo de 2.187 .
} 


\section{O material histologico foi colhido nas seguintes doentes:}

J. J. J., sexo masculino, 24 annos de edade, branco, soldado, natural de Pernambuco (Brasil), removido do quartel onde grassa, na occasião, uma epidemia de alastrim, para o Hospital Central do Exercito e dahi para o Hospital Oswaldo Cruz, onde deu entrada a 22 de Dezembro de 1932, no sexto dia de doença e segundo de exanthema. Mostra, então, uma erupção vesicor pustulosa, com predominancia de vesiculas (Fig. 1). A biopsia (n.o 3.689), feita no segundo dia de erupção, foi praticada na linha mamillar esquerda, junto ao rebordo costal, comprehendendo uma vesicula e uma papula. Evorlução benigna, sem complicações. Alta curado.

B. A., sexo masculino, 23 annos de edade, branco, soldado, natural da Bahia (Brasil), removido do quartel onde grassa, na occasião, uma epidemia de alastrim, para o Hospital Central do Exercito e dahi para o Hospital Oswaldo Cruz, onde deu entrada a 6 de Dezembro de 1932, no quinto dia de doenca e segundo de exanthema. Apresenta uma erupção vesico-pustulosa generalisada, o estado geral sendo bom. Biopsia (n.o 3.647) comprehendendo uma lesãol na linha axillar, região thoraxica, feita entre o segundo e o te:ceiro dias de erupção. Evolução benigna.

M. Alexandre Santos, sexo masculino, 26 annos de edade, mulato, soldado, natural de Alagôas (Brasil), removido do quartel onde grassa, na occasião, uma epidemia de alastrim, para o Hospital Central do Exercito e dahi para o Hospital Oswaldo Cruz onde deu entrada a 30 de Dezembro de 1932. Biopsia (n.o 3.711) de lesão situada no hypochondrio direito, a 31 de Dezembro, no 3.0 dia de erupção e setimo de molestia. O paciente mostra vesiculas e pustulas não numerosas, a doença evoluindo de modo benigno. Alta: curado, em 18 de Janeiro de 1933.

A. V. M., sexo masculino, 21 annos de edade, branco, soldado, natural de Pernambuco (Brasil), removido do quartel onde grassa, na occasião, uma epidemia de alastrim, para o Hospital Central do Exercito e dahi para o Hospital Oswaldo Cruz, onde deu entrada a 28 de Dezembro de 1932. Nunca fôra vaccinado contra a variola. Inicio da doença com symptomas de grippe, apparecendo o exanthema no terceiro dia. Biopsia (n.o 3.622) de lesão da perna feita no terceiro dia de erupção e sexto de molestia, apresentando então o doente uma erupção confluente formada por vesiculas e pustulas (Figs. 2 e 3), o estado geral conservando-se bom. Evolução benigna. Alta curado.

F. S., sexo masculino, 24 annos de edade, mulato, soldado, natural de de Sergipe (Brasil), removido do quartel onde grassa, na occasião, uma epidemia de alastrim, para o Hospital Central do Exercito e dahi para o "Par vilhão Carlos Chagas" do Hospital S. Francisco de Assis, onde deu entrada a 30 de Novembro de 1932. Biopsia (n.o 3.631) de uma vesicula do thorax, na linha mamillar, junto ao rebordo costal, no sexto dia de molestia e terceiro de erupção. Evolução benigna. Alta curado.

M. G. S., sexo masculino, 20 annos de edade, branco, soldado, natural de Sergipe (Brasil), removido do quartel onde grassa, na occasião, uma epidemia de alastrim, para o Hospital Central do Exercito, e dahi para o Hospital Oswaldo Cruz, onde deu entrada a 22 de Novembro de 1932. Chegado recentemente ao Rio, foi então vaccinado pela primeira vez quando declarada a epidemia de alastrim na tropa de que fazia parte. A dociça actual manifestóu- 
se quando o doente ainda apresentava pustulas vaccinicas, iniciando-se com febre, cephaléa e calafrios, symptomas que persistiram durante tres a quatro dias, quando surgiu um exanthema papuloso, seguido de erupção vesiculosa. A 22 de Novembro, no terceiro para o quarto dia de erupção, foi retirada, por biopsia (n.o 3.604), uma vesicula da face interna do antebraço, apresentando o doente um estado geral bom, embora as lesões vesiculo-pustulosas mostrassem tendencia á confluencia. A 24 Novembro no quinto para o. sexto dia de erupgãa foi feita nova biopsia (n.o 3.610) na rẹião eș.capular, sendo retiradas 3 novas lesões. $O$ doente apresentou uma elevação thermicá secundaria, a qual correu por conta de dois abcessos consequentes a injecç̃es subcutaneas. Nessa occasião, a pesquiza bacteriologica (semeadura em meios de cultura) do streptococco no conteúdo de algumas pustulas, resultou negativa. Alta curado.

J. Gonçalves S., sexo masculino, 20 annos de edade, caboclo, soldado, natural do Ceará (Brasil), removido do quartel onde grassa, na occasião, uma epidemia de alastrim, para o Hospital Central do Exercito e dahi para o Hospital Oswaldo Cruz, onde deu entrada a 28 de Novembro de 1932. Biopsia (n.o 3.620) de uma lesão do antebraço, no 11.0 dia de molestia e setimo de exanthema. O doente apresenta estado geral bom e uma erupção vesiculo-pustulosa discreta, mas generalisada, sendo as lesões mais numerosas no rosto e nas mãos (Fig. 4). Evolução benigna. Alta curado:

L. G. Oliveira, sexo masculino, 24 annos de edade, preto, soldado, natural do Piauhy (Brasil), removido do quartel onde grassa, na occasião: uma epidemia de alastrim para o Hospital Central do Exercito e dahi para o "Pavilhão Carlos Chagas» do Hospital S. Francisco de Assis, onde deu entrada a 30 de Novembro de 1932. Biopsia (n.o 3.630) no 11.0 dia de doença e sexto de erupção. Inicio com febre, angina e cephaléa. $O$ exanthema, a principio discreto, depois generalisado, appareceu no 5.0 dia de molestia. Ao ser internado, apresenta o estado geral bom e uma erupção vesiculo-pustulosa emi todo o corpo. Evolução benigna. Alta curado.

Doente de variola vera internado no Hospital S. Sebastião, durante a epidemia de 1926 no Rio de Janeiro. Biopsia (n.o 3.933) de uma vesicula, material que nos foi cedido por obsequio dos nossos collegas Drs. A. Marques da Cunha e Julio Muniz.

\section{INCLUSOES DO ALASTRIM}

Nas biopsias de exanthema do alastrim examinadas, as cellulas epidermicas que mostram inclusões cytoplasmaticas não são tão numlet rosas, nem apresentam localisação tão regular quanto as correspondentes na biopsia de variola, que estudamos para comparação.

Pareceu-nos, comtudo, que ellas mais facilmente eram achadas em cellulas do fundo das vesiculas e vesico-pustulas, não raro nas proprias cellulas pigmentadas da camada basal (Figs. 9, 14 e 16). Tambem as inclusões intranucleares não raro foram encontradas em cellulas pigmentadas (Figs. 22, 23 e 24). De um modo geral, quando encontrado, na lesão, o ponto onde as cellulas epidermicas apresentam 
"inclusões", varios desses elementos, por vezes contiguos, as encerram. No entanto, mais adianle, na mesma lesão, não é possivel de novo encontral-as.

As cellulas que mostram alterações com as caracteristicas geralmente attribuidos ás «inclusões" das doenças de virus foram desenhadas isoladamente, a nossa descripção sendo baseada nesses documentos.

Devemos considerar separadamente, inclusões cytoplasmaticas e inclusões intranucleares.

\section{a) INCLUSÕEs CyTOPLASMATICAS}

As inclusões cytoplasmaticas 'menos volumosas apresentam dimensões semelhantes ou inferiores ás do nucleolo da cellula epidermica .(Fig. 6). De contornos circulares, fortemente coradas em azul (45 C8 do diccionario de Maerz e Paul) em preparados pela hematoxylina-eosina, as inclusões por vezes multiplas e localisadas em zona de cytoplasma afastada do nucleo, são circumdadas por um estreito halo claro. As cellulas que as encerram apresentam nucleo apparentemente normal. $\mathrm{Na}$ figura 6 são ellas representadas em uma cellula epidermica com dois nucleos. De passagem devemos dizer que a divisão das cellulas epidermicas por amitose é assás frequente no exanthema do alastrim, quo nesse parlicular se assemelha ao da varicella.

Nas figuras 7, 8 e 46 (ao centro) são representadas inclusões que occupam região vizinha do nucleo, entrando em contacto com a membrana nuclear apenas em uma parte de sua superficie. Recobrem assim o nuclco á maneira de um pequeno gorro. Fortemente coradas em azul violeta nos preparados pela hematoxylina-eosina, ellas ora apresentam estructura apparentemente homogenea (Fig. 8), ora nitidamente vacuolada (Figs. 9 e 46, á direita). Outras vezes (Fig. 45) a inclusão applica-se intimamente de encontro á membrana nuclear, acompanhando os contornos do nucleo em extensão maior ou menor. O nucleo de taes cellulas é distinctamente tumido, conforme se póde ver comparando as figs. 7,8 e 9 , com a figura 5 , a qual representa cellulas epidermicas normaes no 'mesmo córte histologico. Devemos, porém, mencionar que, ao contrario do que acontece na variola e na vaccina, taes inclusões cytoplasmaticas juxtanucleares não mostram, no alastrim, tendencia a deformarem o nucleo, produzindo em sua superficie uma depressão onde se alojam. O halo claro do cytoplasma permanece circum:scripto á vizinhança immediata da inclusão, quando não falta inteiramente (Fïgs. 45 e 46). A cellula epidermica, afóra a inclusão, apenas se distingue da normal pelo aspecto tumido do nucleo. 
Nas figuras 10 e 11 são representadas inclusões mais volumosas, correspondendo, por vezes, ao terço do nucleo das cellulas que as encerram. Taes inclusões, representadas ainda na figura $10 \mathrm{em}$ uma cellula epidermica com dois nucleos, occupam a vizinhança immediata do nucleo, envolvendo-o e contornando-o sem de modo algum deformal-o como faria um chumaço de algodão em torno de uma formação solida. Esta dispasição é difficil de ser representada, quer em desenhos, quer em photographias (Fig. 46, ao centro), visto como o plano de focalisação da inclusão no ponto em que ella envolve o nucleo, não permitte a focalisação do priprio nucleo. As inclusões ainda se mostram coloridas em azul violeta, mais accentuado naquellas onde a estructura é mais homogenea (Fig. 10), mais pallido nas que revelam estructura vacuolada (Fig. 11):

Inclusões cytoplasmaticas mais volumosas são illustradas nas figuras 14, 18, 15 e 16. O aspecto vacuolado em taes inclusões de grande volume é feição muito apparente em algumas dellas (Fig. 15). A sua fórma é irregular, conservando, ainda, affinidade de coloração pela hematoxylina. Embora frequentes vezes unicas, não são comtudo raros os aspectos vistos nas figs. 13 e 47 , onde duas inclusões de tamanho diverso, se dispõem na visinhança de polos oppostos do nucleo, e o da fig. 9, onde duas inclusõas de fórma differente occupam, no cytoplasma, região visinha uma da outra.

Tal como nas cellulas epidermicas com inclusões de volume comıparavel ao do nucleo, os nucleos de cellulas com inclusões cytoplasmaticas ás vezes tão volumosas quanto elles mesmo (Fig. 16), ordinariamente conservam estructura normal. Mostram nitida membrana nuclear, a chro. matina disposta em grumos delicados sobre um reticulo de linina, no qual apparecem um a tres nucleolos. Estes ultimos ás vezes são nitidamente coloridos pela eosina (Figs. 13, 15, e 16), outras corami-se em azul violeta (Fig. 18).

Insistimos em affirmar que, de modo algum, taes nucleos suggerem pycnose, karyorhexis ou karyolyse. Apresentam, comtudo, tumefacção ás vezes consideravel (comparar as figs. 13 e $18 \mathrm{com}$ a fig. 5).

Outro detalhe a referir é a extensão frequentemente pequena que apresenta o halo do cytoplasma em torno da inclusão (Figs. 11, 16 e 18). Algumas vezes, porém, a zona de cytoplasma sem estructura apparente é extensa e mostra relação menos evidente com as inclusões (Figs. 12, 15 e 17). Em taes casos, comtudo, nunca se vê uma linha de demarcação nitida entre a zona vacuolada e a de cytoplasma com estructura conservada. 
$\mathrm{Na}$ figura 17 está representada uma cellula epidermica com diversos nucleos, resultantes de activa multiplicação por amitose. Conforme dissemos atraz, cellulas epitheliaes multinucleadas são abundantes no exanthema do alastrim, o que approxima o aspecto histologico ahi visto do da varicella. A inclusão cytoplasmatica nella se apresenta esbatida e mal definida, aspecto este por vezes visto nas grandes inclusões cytoplasmaticas do alastrim, especialmente quando a zona clara do cytoplasma é extensa.

A fig. 41 representa uma cellula epidermica pigmenlada (camada basal) com inclusão cytoplasmatica do alastrim, em preparado corado pelo methodo de Unna modificado (hematoxylina-safranina). Os nucleolos são corados em roseo-avermelhado pela safranina. A inclusão cytoplasmatica, de fórma triangular, occupa a visinhança do nucleo, mostrando uma leve coloração azulada. Essa ausencia de affinidade corante para a safranina distingue as inclusões do alastrim tanto no homem. como no Macacus rhesus das inclusóes cytoplasmaticas da variola vera e da vaccina, nitidamente safraninophilas (Torres e Teixeira, 193 $\downarrow$ ) .

Notamos, ainda, inclusões cytoplasmaticas basophilas, estreitas e alongadas (Fig. 9). Em certos casos taes inclusões juxtapõem-se á membrana nuclear, acompanhando os contornos do nucleo em metade de seu perimetro, quasi sempre ao longo do seu maior diametro. Tambelm ellas se moldam, sobre o nucleo, sem de modo algum, deformal-o.

Não é raro encontrar inclusões cytoplasmaticas do alastrin em cellulas cpidermicas com degenerescencia hydropica (Figs. 9 e 16). Apresentam ellas, então, além da inclusão, ora proximo della, ora, mais frequentemente, em zona afastada, uma ou mais cavidades sem estructura apparente (vacuolos). O nucleo de taes elementos é, por vezes, deformado e enrugado, outras vezes normal em seus contornos. Ao lado do cellulas com inclusões, occorrem numerosas outras que não as encerram mas são attingidas, egualmente, pela degenerescencia hydropica.

E, assim, necessario distinguir o halo claro que circumda immediatamente a inclusão cytoplasmatica, dos vacuolos occorrendo na "retikulierende Degeneration» e na degenerescencia hydropica. Essa distincção é por vezes impossivel de ser feita quando as inclusões e os precessos degenerativos acima citados combinam-se na mesma cellula.

\section{b) INCLUSÕES INTRANUCLEARES}

Ordinariamente as cellulas que apresentam inclusões cytoplasmiticas não são as mesmas que contem inclusões intranucleares. Comtudo, occasionalmente estes dois typos de lesão podem se achar associadqs. num mesmo elemlento (Fig. 22). 
Na figura 19 é representada uma cellula epithelial cujo nucleo tumido mostra um reticulo oxyphilo, e encerra maior quantidade de material corado pela eosina que um elemento normal. Na mambrana nuclear, a basichromatina é abundante e ahi constitue espessamentios definidos e circumscriptos. Esse aspecto evidentemente não representa uma inclusão intranuclear typica. E provavel, comtudo, que corresponda a uma phase inicial de sua formação.

As figs. 20, 21, 22, 23 e 24 representam os aspectos encontrados no nosso material de alastrim que mais se approximam das "inclusĩes intranucleares» das doenças por ultravirus.

$\mathrm{Na}$ figura 20 está representada uma cellula epidermica pigmentada que soffreu a "ballonierende Degeneration». O nucleo, entumescido, mostra nitida hyperchromatose discontinua da membrana nuclear contra a qual se acha applicado o nucleolo. O nucleoplasma apresenta uma coloração rosea diffusa e um reticulo acidophilo que se insere, de modo regular, sobre a membrana nuclear.

A fig. 21 mostra uma cellula epidermica com dois nucleos deformados. A basichromatina é presente e abundante sobre a membrana nuclear, formando, além disso, grumos que estão depositados sobre um reliculo. Alguns de taes grumos são mais pallidamente corados em sua porção central que em seus bordos. No nucleoplasma vê-se espaços claros, de fórma irregular, que se interpõem entre a membrana nuclear e material acidophilo situado na porção central do nucleoplasma. Esse material oxyphilo acha-se contido nas malhas de um reticulo corado pallidamente pela eosina.

$\mathrm{Na}$ figura 22, a inclusão intranuclear, de aspecto retiforme, occupa a porção central do nucleoplasma, prendendo-se, de outro lado, á membrana nuclear por delgados filamentos acidophilos. Em sua porção central está contido o nucleolo tumido e sobre cujos bordos apparecem granulos de basichromatina. Outros granulos de basichromatina são vistos um pouco mais afastados e depositados sobre o material oxyr philo. A basichromatina incrusta a membrana nuclear sob a fórma de espessamentos discontinuos. E uma cellula epidermica pigmentada, que contem, além disso, uma inclusão cytoplasmatica.

As figs. 23 e 24 representam phases adiantadas das inclusões intranucleares do alastrim. Os nucleos são tumidos, a basichromatina desapparecida inteiramente do nucleoplasma, constitue espessamentos discontinuos na membrana nuclear, dando-lhe aspecto de linha ponteada. o nucleoplasma apresenta espaços claros, sem nenhuma estructura apparente, de fórma irregular, e contem ora um reticulo espesso, pallidamente corado pela eosina (Fig. 23), ora material acidophilo em maior 
quantidade, no qual o aspecto retiforme é menos evidente. Um nucleolo tumido, pallidamente corado em roseo e contendo uma pequena zona chromophoba é visto na figura 23. A figura 24 mostra marginação do nucleolo cuja affinidade de coloração para com a eosina é diminuidáa.

$\mathrm{Na}$ figura 25 são representados nucleos enrugados, com a membrana levemente espessada, e cujo nucleoplasma é uniformemente coiorido pela eosina. Não temos certeza de que esses aspectos tenham relação com verdadeiras "inclusões intranucleares》.

0 《aspecto retiforme» typico das inclusões intranucleares do alastrim, e, tambem, a marginação da basichromatina, são bem apreciaveis na figura 43 e sotretudo na 44 . Sendo um documento photographico, illustra essa ultima figura os seguintes caracteres importantes de uma inclusão intranuclear typica do alastrim: 1) aspecto retiforme do material acidophilo, que occupa certas porções do nucleoplasma, sendo sẹparado da membrana nuclear por zonas claras, sem estructura apparente; 2) condensação da basichromatina sobre a membrana nuclear, ahi formando depositos de espessura discontinua; 3) augmento de volume e tumefacção do nucleo. Nota-se, ainda, marginação do nucleolo.

\section{RESUMO}

Baseados nas descripções e documentos atraz analysados, podemos concluir que os caracteres geraes apresentados pelas inclusões cytoplasmaticas do alastrim no homem são: a sua ausencia de coloração pela safranina em preparados pelo methodo de Unna modificado (Fig. 41), a sua reacção basophila em preparados pela hematoxylina-eosina, traduzida pela tonalidade azul-violacea de coloração que apresentam (Figs. 7-16 e 18), a sua tendencia, quando attingem grandes dimensões, de permanecerem unicas ou solitarias em cada cellula epidermica (Figs. $14,15,16$ e 18), embora não seja rara a dispasição em polos oppostos do nucleo (Figs. 13 e 47).

As inclusões cytoplasmaticas frequentemente se adossam ao nunucleo (Figs. 7, 8, 45 e 46). Este, porém, conserva contornos perfeitamente normaes, a inclusão cytoplasmatica envolvendo-o sem deformal-o.

Devemos, ainda, accrescentar que as cellulas epitheliaes do honıem com inclusões cytoplasmaticas do alastrim não raro conservam um cytoplasma normal fóra da zona das inclusões (Figs. 45 e 46). Outras vezes, na zona immediatamente adjacente a esta, existe um halo como que representando uma estreita zona de retracção (Fig. 18).

Quanto ás inclusões intranucleares do alastrim, ellas se apresentam menos caracteristicas do que as notadas em outras taes as da febre 
amarella (Torres, 1929), as do herpes zoster (Lipschütz, 1920), as da varicella (Tyzzer, 1905) e, especialmente, as da variola vera.

Assim é que o material acidophilo intranuclear cora-se pallidamente pela eosina, não se condensando em uma estructura central nitidamente separada da membrana nuclear por uma area de nucleoplasmia sem estructura, tal como succede em phases typicas da maioria das inclusões das doenças de virus.

A marginação da basichromatina e sua deposição sobre a membrana nuclear apparece, porém, de modo typico e comparavel ao descripto nas demais inclusões intranucleares.

Nunca pudemos encontrar o aspecto de corpusculos acidophilos intranucleares distinctos de contornos nitidos e fórma regular, contendo por vezes, zonas chromophobas. Tal aspecto é typico nas inclusões intranucleares da variola vera.

$\mathrm{O}$ aspecto que nos parece typico, na inclusão do alastrim, é o representado nas figs. 21 e 44 , atraz mencionado com "aspecto retiforme».

Identico aspecto apresentam as inclusões intranucleares do alastrim em cellulas epidermicas do Macacus rhesus conforme demonstra a figura 22, estampa XXIX, do trabalho de Torres e Teixeira (1934a).

\section{INCIDENGIA DAS "INCLUSÕES " NAS LESOES EPIDERMICAS}

\section{DO ALASTRIM}

Com o fim de obter informações sobre a incidencia das inclusões nas diversas phases evolutivas das lesões epidermicas do alastrim e suas relações com outras alterações, especialmente a "ballonierende Diegeneration", examinamos systematicamente todas as lesões epidermicas bem caracterisadas existentes em nosso material. O resultado está annotado no Quadro n. ${ }^{\circ} 1$.

Deixamos de lado, nessa estatistica, as lesões localisadas em torno de folliculos pilo-sebaceos e glandulas sudoriparas.

Em 12 lesões epidermicas do alastrim examinadas, 11 mostravam inclusões cytoplasmaticas, especialmente abundantes nos estadios de papula e de vesicula. As inclusões intranucleares existiam apenas em 3 lesões, das quaes duas pustulas e uma vesicula em inicio de suppuração. A sua presença achava-se associada á da "ballonierende Degeneration", a qual era encontrada, apenas, nas tres lesões que mostravam inclusões intranucleares. 
Quadro 1

\begin{tabular}{|c|c|c|c|}
\hline $\begin{array}{l}\text { Lesões epidermicas do } \\
\text { alastrim nas phases de : }\end{array}$ & Inclusões cytoplasmaticas & Inclusões intranucleares & $\begin{array}{c}\text { "ballonierende Dege- } \\
\text { neration" }\end{array}$ \\
\hline $\begin{array}{l}\text { Papula } \\
\text { Material no. } \\
\quad 3596 \\
\quad 3711 \text { lesæa a }\end{array}$ & ++ & - & - \\
\hline $\begin{array}{l}\text { Vesicula } \\
\text { Material no. } \\
3610 \text { lesão a } \\
\text { lesão b } \\
3604 \text { lesão b } \\
3711 \text { lesâ }\end{array}$ & $\begin{array}{l}+ \\
+ \\
+\end{array}$ & $\begin{array}{l}- \\
-\end{array}$ & $\begin{array}{l}- \\
-\end{array}$ \\
\hline $\begin{array}{l}\text { Vesicula em inicio } \\
\text { de suppuração } \\
\text { Material no. } \\
3631\end{array}$ & + & + & $t$ \\
\hline $\begin{array}{l}\text { Pustula } \\
\text { Material no. } \\
3647 \text { lesão a } \\
\text { lesão b } \\
3989 \\
3622\end{array}$ & $\begin{array}{l}+ \\
+ \\
+\end{array}$ & $\frac{+}{+}$ & $\frac{+}{t}$ \\
\hline $\begin{array}{l}\text { Pustula em deseccaçã } \\
\text { Material no. } \\
3603\end{array}$ & - & - & - \\
\hline
\end{tabular}

\section{ALTERAÇOEES NUCLEOLARES DO ALASTRIM}

Tal como as cellulas hepaticas na febre amarella, as cellulas epidermicas nas lesões do alastrim, mostram, em gráo apreciavel, multiplicidade de nucleolos. Nas cellulas das paredes das vesiculas e em elementos adjacentes, é commum encontrar nucleos contendo tres, ás vezes quatro e cinco nucleolos differentes. Ao mesmo tempo, taes nucleos se apresentam tumidos, embora as cellulas não apresentem inclusões cytoplasmaticas ou intranucleares.

Como alteração nucleolar digna de referencia, visto como simula, até certo ponto, as verdadeiras inclusões intranucleares, mencionaremos a tumefacção e lobulação dos nucleolos (Figs. 26 e 47, em cima), aspectos que não são raros nas cellulas epidermicas das lesões de alastrim e nas da zona circumvisinha, onde tambem occorrem tumefacção dos nucleos, multiplicação por amitose e figuras de caryokinese

O nucleolo, ou os nucleolos existentes em cada nucleo auginentam de volume, tornando-se, ao mesmo tempo, menos chromophilos que 
em condições normaes. Os seus contornos, por vezes regulares, mais frequentemente mostram-se sinuosas e recortados. Pouco a pouco a sua configuração torna-se cada vez mais irregular, em 8 de cifra, em ' $T$ ou então nitidamente polylobulados. Em certos casos, os nucleolos, modificados, se apresentam como uma faixa acidophila occupando a parte central do nucleoplasma e orientada no sentido do maior diametro do nucleo. O reticulo de linina, com pequenos granulos de chromatina, parece ligar essa massa acidophila central á membrana nuclear, na qual existe moderado grau de hyperchromatose.

Nos nucleos com taes alterações nucleolares, a basichromatina, sob a fórma de pequenos granulos, é geralmente conservada no reticulo de linina (Fig. 26); um ou mais granulos de chromatina, mais volumosos e mais intensamente corados que os demais, por vezes se localisam nos bordos ou no interior dos nucleolos tumidos e lobulados. Comtudo, taes nucleos com alterações nucleolares podem apresentar uma leve hyperchromatose da membrana nuclear, o que reforça a sua semelhança com as verdadeiras inclusões intranucleares das doenças por ultravirus.

Alguns dos aspectos acima referidos, especialmente a lobulação dos nucleolos (Figs. 26 e 47, em' cima) poderiam ser explicados por movimentos ameboides daquellas estructuras, movimentos que soffreriam intensificação em determinadas circumstancias. Heidenhain diz, com effeito: "Es ist also gar kein Z $Z$ weifel, dass an den Nukleolen. Bewegunserscheinungen vorkommen, welche denen amöboider Art äusserlich ähnlich sehen» (Heidenhain, 1907, Erste Lieferung, S. 184).

\section{INCLUSOEES DA VARIOLA}

$\mathrm{Na}$ biopsia de vesicula de variola vera que examinamos eram muito numerosas as cellulas epitheliaes com inclusões cytoplasmaticas e intranucleares

Tal como vimas no alastrim, esses dois typos de inclusões occorrem em elementos cellulares differentes.

As inclusões cytoplasmaticas são mais abundandes em cellulas da porção média do corpo mucoso, em região immediatamiente vizinha á vesicula. E commum, então, observar campos nos quaes a totalidade das cellulas epitheliaes as apresentam.

Ao contrario, as cellulas com inclusões intranucleares occupam de preferencia a região do fundo da propria vesicula e são, as mais das vezes, elementas attingidos pela "ballonierende Degeneration».

Tal como fizemios com as do alastrim, examinaremos, separadamente, as inclusões cytoplasmaticas e as intranucleares. 


\section{INCLUSÕES CYTOPLASMATICAS}

$\mathrm{Na}$ figura 27 são representadas duas inclusões cytoplasmaticas de fórma irregularmente redonda, coradas em roseo em preparados pela hematoxylina-eosina. A menor, do tamanho do nucleolo, occupa uma depressão á superficie do nucleo. A maior, situada em zona do cytoplasma afastada do nucleo, mostra nitido aspecto vacuolado.

A figura 28 representa duas inclusões mais volumosas que o nucleolo, uma corada intensamente pela eosina, outra tinta pela hematoxylina. O halo claro perinuclear onde estão tambem conìdas as inclusões é nitidamente separado da porção restante do cytoplasına por uma linha ou membrana corada em roseo pela eosina.

Nas figuras 29, 30,31 e 32 são representadas inclusões multiplas em cada cellula. São em geral de fórma irregularmente arredondada e coradas pela eosina. O seu aspecto, ora é homogeneo (Figs. 29, 30 e 31), ora nitidamente vacuolado (Fig. 32). O volume das inclusões é variavel, não só de cellula para cellula, como na mesma cellula considerada. As maiores, porém, nunca alcançam volume egual ao do proprio nucleo da cellula epidermica. Em todas as cellulas com inclusões cytoplasmaticas, nota-se aspecto claro do cytoplasma em zona de extensão variavel, mas sempre consideravel e geralmente não circumscripta á visinhança immediata da inclusão. A linha ou membrana rosea que separa essas zonas vacuoladas do cytoplasma de outras onde o cytoreticulo se apresenta conservado é bem nitida nas figs. 31 e 32 .

Os nucleos das cellulas com inclusões cytoplasmaticas conservam, por vezes, aspecto normal (Fig. 28). Outras vezes, mostram multiplicidade de nucleolos (Fig. 30). Na maioria das cellulas, porém, elles se mostram deformados e, por vezes, pycnoticos (Figs. 27 e 32 ).

$\mathrm{Na}$ fig. 42 a inclusão da variola apresenta-se corada pela safranina em tonalidade semelhante á dos nucleolos da cellula, occupando uma grande zona de cytoplasma apparentemente sem estructura. O methodo de coloração é o de Unna modificado (hematoxylina-saf:tunina). Convem lembrar que foi baseado, em parte, no methodo original de Unna, que Hammerschmidt chegou á conclusão de que os corpusculos de Guarnieri se originariam por um processo de extrusão do nucleolo.

\section{INCLUSÕES INTRANUCLEARES}

A fig. 33 representa, a nosso ver, uma phase inicial de formação das inclusões intrenucleares na variola vera. A membrana nuclear passue espessura normal, mas a zona de succo nuclear encerra quantidade apreciavel de material acidophilo condensado em 4 massas de ta- 
manho desigual. Não é possivel, nesse nucleo, identificar o nucleolo, embora não seja improvavel que a massa acidophila maior represente aquella estructura.

A fig. 34 representa duas cellulas epidermicas situadas em um "lambeaux» epithelial que permanecia conservado no fundo da vesicula. As cellulas ahi mantem relações reciprocas inalteradas, não mostrando o aspecto de elementos attingidos pela "ballonierende Degeneration : : Apezar disso, em seus nucleos existem inclusões intranucleares sob a fórma de granulos acidophilos isolados em um nucleoplasma sem estructura apparente (cellula inferior), e de um reticulo oxyphilo contendo em suas malhas material acidophilo, separado da membrana nuclear por areas de nucleoplasma sem estructura apparente (cellula superior).

Nas figuras $35,36,37$ e 38 são representadas inclusões intranucleares da variola caracterisadas por intensa coloração vermelha que apresentam nos preparados corados pela hematoxylina-eosina. A fig. 35 mostra, ainda, granulos de basichromatina conservados na zona de succo nuclear, o material acidophilo que constitue a inclusão sendo menos abundante que nas figuras seguintes. Na fig. 36, o nucleolo applicado de encontro á membrana nuclear deformada e espessada, distingue-se clas inclusões pela tonalidade vermelha escura de sua coloração. A inclusão é representada por duas massas de tamanha desigual, fortemente tintas pcla cosina. Esta cellula provem da camada basal e contem pigimento.

O nuclcolo é, tambem, distinguido com facilidade, junto á membrana nuclear, na fig. 37 , e, com difficuldade, parecendo incrustado naquella membrana, na fig. 35 .

As cellulas epidermicas com inclusões intranucleares são, em sua maioria, attingidas pela «ballonierende Degeneration». Isoladas ou desligadas das cellulas adjacentes, ellas mostram um contorno que tendei a se arredondar. A necrose nellas se traduz, ainda, pela homogenisação c forte acidophilia do cytoplasma (Figs. $35,36,37$ e 38).

$O$ 'material fortemente acidophilo que forma a inclusão intranuclear da variola por vezes parece homogeneo (Figs. 35,36 e 37). Outras vezes, porém, mostra minusculas zonas claras, simulando pequenos vacuolos (zonas chromophobas) (Fig. 38). A substancia acidophila, além' disso, mostra intensidađe de coloração variavel (Fig. 38).

Nas figs. 39 e 40 , as cellulas epidermicas coradas pelo methodo de Unna, mostram aspectos typicos das inclusões intranucleares. A membrana nuclear fortemente espessada e corada pela hematoxylina (marginação de basichromatina) limita um nucleoplasma claro dentro do qual 
apparecem corpusculos de pequenas dimensões, corados pela safranina, de fórma espherica ou ovoide, com contornos muito nitidos. Por vezes unicos (Fig. 39), as mais das vezes são multiplos e de dimensões variaveis (Fig. 40). Encerram taes corpusculos intranucleares, uma ou varias pequenas areas chromophobas, geralmente uma maior e outras menores.

\section{RESUMO}

Resulla das descripções e documentos examinados que as inclusões cytoplasmaticas da variola vera, no material humano examinado, apresentam caracteres geraes que poderão ser assim resumidos: 1. intensa coloração pela safranina nos preparados pelo methodo de Unna modificado (Fig. 42), mostrando a inclusão matiz scmelhante ao dos nuclcolos da mesma cellula. 2. reacção predominantemente acidophila nos preparados pela hematoxylina-eosina, traduzida pela tonalidade rosca ou vermelha de coloração (Figs. 27, 29, 30, 31 e 31). 3. frequente multiplicidade de inclusões de fórma e dimensões variadas na mesma cellula (Figs. 29 e 30), as maiores inclusões (Figs. 29 e 32), scndo menores que as grandes inclusões cytoplasmaticas solitarias do alastrim (Figs. 15, 16 e 18).

E a regra, ainda, observar-se desapparecimento de qualquer estruclura no cytoplasma das cellulas com inclusões em zona muito exlensa, tornando-se difficil explicar tal aspecto unicamente pela retracção das inclusões no acto da fixação (Figs. 31 e 32 ).

Quanto ás inclusões intranucleares, ellas se apresentam sob tres aspectos, dois dos quaes bem reconhecidos por Luger e Lauda (1926).

Em um primeiro aspecto, o nucleo conserva, em parte, o reticulo de linina e encerra uma massa irregular (Fig. 35) ou, então, pe(quenas massas e granulos de dimensões variaveis (Figs. 33 e 34) constiluidos por material acidophilo que ahi não existe em condições normạs. A 'membrana nuclear tem espessura visinha do normal.

Em um segundo aspecto, a inclusão occupa a totalidade do nucleoplasma (Fig. 3), apenas separado da membrana nuclear, em alguns casos (Fig. 38), por um estreito espaço claro (zona de retracção). Por vezes apresenta um aspecto homogeneo (Fig. 37); outras vezes a inclusão mostra pequenas areas chromophobas (Fig. 38). A hyperchromatose da membrana nuclear é accentuada, tanto neste como no aspecto seguinte.

No terceiro aspecto (aspecto corpuscular) (Figs. $39,40,48 \mathrm{c}$ 50), a inclusãn intranuclear é formada por um ou mais corpusculos acido- 
philos, de contornos muitc nitidos e fórma regular, ora ovoide, ora espherica. No interior de cadia corpusculo, apparecem zonas chromophobas multiplas, sendo ordinariamente uma maior que as outras (Figs. 39, 40, 48 e 50). Fóra desses corpusculos, o nucleoplasma contem, por vezes, material menos intensamente corado pelo eosina ou pela safranina (Figs. 40). O reticulo de linina, porém, acha-se completamente desapparecido, e não raro se observa, em torno dos corpusculos acidophilos, uma zona algum tanto extensa de nucleoplasma sem nenhuma estructura apparente (Fig. 48, á direita).

Frisamos o modo peculiar de se comportar o nucleolo nas cellulas epidermicas com inclusões intranucleares da variola. Recalcado, a principio, de encontro á membrana nuclear (Fig. 36), elle em seguida é englobado pela propria membrana nuclear, parecendo incluso nessa estructura (Figs. 37, 35, 38 e 48, á direita). A "marginação» do nucleolo, e o seu englobamento ou inclusão na membrana nuclear, bem comı o terceiro aspecto que descrevemos, de corpusculos intranucleares esphericos ou ovoides com zonas chromophobas, são caracteres que differenciam, de modo nitido, as inclusões intranucleares da variola vera da das demais inclusões das doenças de virus.

Nem sempre, porém, os aspectos encontrados podein ser incluidos, com facilidade, em um dos tres grupos atraz mencionados, o que indica a existencia de phases de transição entre elles.

Tal como assignalou Ewing, as cellulas epidermicas com inclusões intranucleares são geralmente as altingidas pela "ballonierende Degeneration». Em geral taes elementos revestem o fundo da vesicula, ás vezes formando uma unica camada, e representando tudo o que resta da epiderme. Comtudo, em nosso material, conseguimos encontrar inclusões intranucleares em cellulas espicuhosas do corpo mucoso de Malpighi que ainda conservavam relaçčes normaes com os elementos contiguos e não eram attingidas vela «ballonierende Degeneration». Em taes inclusões é que, de preferencia, observamos o aspeclo de granulos mencionado no grupo I (Fig. 34). A hyperchromatose da memlbrana nuclear é, então, pouco notavel, contrastando com o grau pronunciado que apresenta nos dois outros aspectos. Existiam, ellas em «lambeaux» epitheliaes, presos em certos pontos, por estreito pediculo, á camada basal, no fundo da vesicula.

\section{DISCUSSÃO}

A comparação entre as inclusões do alastrim e as da variola vera em material humano revelou entre ellas differenças nitidas. 
As inclusões cytoplasmaticas mostram differença de tamanho, sendo as do alastrim (Figs. 14, 15, 16 e 18) sensivelmente mais volumosas que as da variola vera (Figs. 29 e 32) quando consideradas, nos dois casos, inclusões com dimensões maximas.

Mostram, ainda, differenças notaveis em suas propriedades corantes, sendo que as inclusões do alastrim não se coram pela safranina em preparados pelo methodo de Unna (Fig. 41), ao passo que as da variola vera apresentam accentuada safraninophilia (Fig. 42), de longa data conhecida (Guarnieri, Hammerschmidt, Paul), e revelavel, de modo vantajoso, por aquelle processo de coloração. Differenças de coloração são apreciaveis mesmo em preparados pela hematoxylina-eosina. As inclusões cytoplasmaticas do alastrim coram-se, de modo nitido, pela hematoxylina (basophilia), não só quando de pequenas dimensões (Fig. 6) como ainda quando de dimensões maximas (Figs. 14, 15, 16 e 18). As da variola vera, ao contrario, são ordinariamente coradas pela eosina (acidophilia), por vezes mesmo de modo intenso (Figs. 27, 29, $\mathbf{3 0}$. 31 a, 32).

Se algumas inclusões cytoplasmaticas da variola, as "kappenartig dem Kerne aufsitzende Grebilde, ähnlich wie bei Verruga peruviana", correspondem, segundo Paschen (1934) a colonias do agente, o facto do seu aspecto e das suas reacções de coloração não serem identicos nas lesões cutaneas da variola vera e do alastrim, constitue, sem duvida; um argumento morphologico a ser aproveitado pelos que não acceitam a identificação das duas molestias.

O contraste, porém, resalta ainda mais pronunciado quando comparadas entre si, as inclusões intranucleares do alastrim $\mathrm{e}$ as da variola vera que julgamos typicas, para cada uma dellas, o "aspecto retiforme» das inclusões do alastrim (Fig. 44), e o «aspecto corpuscular" das da variola vera (Figs. 40 e 48). Nunca encontramos, no nosso material de variola vera, o aspecto retiforme das inclusões do alastrim, e tambem. de outro lado, nunca conseguimos evidenciar, no nosso material de alastrim. o aspecto corpuscular das inclusões intranucleares da variola vera.

Chegamos, assim, ao resultado de que, no material humano examinado, as inclusões cellulares do alastrim não são identicas ás da variola vera, quer se tome em consideração as inclusões cytoplasmaticas, quer as intranucleares. Por outro lado, o facto dessas inclusões cellulares serem perfeitamente identicas em uma serie de 12 lesões colhidas em oito doentes diversos de alastrim, é contrario á possibilidade de representarem as differenças notadas, simples variações individuaes.

Os dois quadros seguintes facilitam a apreciação das differenças notadas. 


\section{Quadro 2}

Comparação entre as inclusões cytoplasmaticas do alastrim e as da variola vera no homem.

\section{Alastrim}

1. Em preparados pelo methodo de Unna modificado (hematoxylina-safranina), as inclusões mostram uma pallida coloração azul, semelhante á do cytoplasma. Fazem, então, grande contraste com os nucleolos da cellula tintos intensamente em vermelho.

2. Em preparados pela hematoxylinaeosina, as inclusões coram-se pela hematoxylina, em tonalidade que varia do azul-violaceo claro ao violeta escuro.

3. As inclusões são, geralmente, pouco numerosas em cada cellula epithelial, sendo frequentemente solitarias ou em um par disposto em polos oppostos do nucleo. As inclusões solitarias são de dimensões maiores que as mais volumosas encontradas no material de variola vera examinado.

\section{VARIOLA VERA}

1. Em preparados pelo methodo de Unna modificado (hematoxylina-safranina), as inclusões tingem-se em vermelho, com intensidade e em maliz semelhante á dos nucleolos das cellulas epidermicas respectivas (safraninophilia).

2. Em preparados pela hematoxylinaeosina, as inclusões coram-se pela eosina, em tonalidade variando do roseo-claro ao vermelho. Exceptionalmente, em uma mesma cellula apparecem, ao lado de inclusões coradas em roseo, outras tintas em azul pela hematoxilina.

3. As inclusões constituem, ordinariamente, duas ou mais formações, de tamanho e dimensões variaveis, scndo assim multiplas dentro de uma mesma cellula epithelial. As de maiores dimensões não alcançam o tamanho das grandes inclusões solitarias do alastrim. 
4. E frequente a localisação juxta-nuclear da inclusão, envolvendo ella o nucleo á maneira de um gorro ou de um chumaço de algodão. Comtudo, as inclusões nunca se alojam em depressões da superficie do nucleo, o qual conserva aspecto normal de seus contornos.

5. No cytoplasma das cellulas com inclusores existe um halo claro, sem estructura apparente, localisado, na maioria dos casos, na visinhança immediata da inclusão.

6. Nas phases de vesicula e de pustula, as cellulas com inclusões não eram numerosas. Só existiam em alguns campos microscopicos, ao mesmo tempo em cellulas epidermicas contiguas, quer nas paredes lateraes da vesico-pustula, quer no fundo da lesão.
4. 'Tal como acontece aos corpusculos de Guarnieri da vaccina, as inclusões cytoplasmaticas da variola, em certos casos, se alojam em depressões da superficie do nucleo.

5. Frequentemente o cytoplasma das cellulas com inclusões apresenta extensa zona sem nenhuma estructura apparente, a qual excede de muito a area onde se acham as inclusões. Por vezes, uma linha sinuosa, corada em roseo nos preparados pela hematoxylina-eosina, estabelece a separação entre essa zona e aquella onde o cytoreticulo se acha conservado.

6. Em uma biopsia de vesicula, as cellulas com inclusões eram muito numerosas na zona media do corpo mucoso de Malpighi, na região immediatamente visinha aquella onde se formara a vesicula (paredes lateraes da vesicula). 


\section{Quadro 3}

Comparação entre as inclusões intranucleares do alastrim $e$ as da variola vera no homem.

\section{Alastrim}

1. Em cortes pela hematoxylina-eosina, as inclusס̃es intranucleares apparecem sob a fórma de um reticulo pallidamente corado em roseo (aspecto retiforme), occupando extensão variavel do nucleoplasma. Porçб̃es de nucleoplasma sem estructura apparente separam-no de modo discontinuo, da membrana nuclear. Em nenhum caso as inclusões revestem a apparencia de pequenos corpusculos intranucleares, tal como na variola vera (aspecto corpuscular).

2. A membrana nuclear é espessada, a basichromatina nella constituindo depositos discontinuos menos consideraveis que os vistos na variola vera.

3. O nucleo com inclusão intranuclear é augmentado de volume.
VARIOLA VERA

1. Em cortes pela hematoxylina-eosina, as inclusões intranucleares coram-se intensamente em roseo-avermelhado. Ás vezes, a inclusão é unica, occupando grande extensão do nucleoplasma, sendo representada por um material de estructura ora homogenea, ora contendo pequenos espaços claros (zonas chromophobas). Outras vezes as inclusóes revestem $o$ aspecto de pequenos corpusculos intranucleares distinctos entre si (aspecto corpuscular). Solitarios, ou em numero de dois oll de tres, são elles cercados por uma zona de nucleoplasma sem estructura apparente. E caracteristica desses curpusculos a nitidez de seus contornos, e encerrarem zonas chromophobas, ás vezes uma unica, outras vezes uma maior e varias menores.

2. A membrana nuclear é consideravelmente espessada, em consequencia da marginação de quantidade notavel de basichromatina. $O$ espessamente é frequentes vezes continuo, outras disconlinuo.

3. O nucleo com inclusão intranuclear é diminuido de volume.

Já que nos occupamos, de modo especial, das inclusões intranucleares do alastrim e da variola vera, vem a proposito referirmos aqui a confusão que forçosamente traz ao assumpto, o emprego de designaçães 
diversas para um mesmo aspecto e, de outro lado, a accepção differente que lhes conferem autores diversos.

E o caso das duas expressões: "inclusão intranuclear " e «degenerescencia oxychromatica».

A expressão "inclusão» quando applicada a modificações cellulares especificas das doenças por ultravirus vae tendo cada vez maior acceitação, pelo facto de não subentender nenhuma concepção á priori. Tanto se applica, com propriedade, a um processo puramente degenerativo, no qual o material revelavel ao exame histologico seja constituido, unicamente, por estructuras pathologicas oriundas dos proprios componentes cellulares, como a estructuras formadas em sua totalidade, ou em parte, por micro-organismos ou formações a elles directamente ligadas.

Quanto á expressão "degenerescencia oxychromatica», ella foi, pela primeira vez, usada por Luger e Lauda (1926) em relação aos processos nucleares especificos observados no herpes simplex, herpes zoster, varicella, variola humana e variola das carpas. Era uma expressão que traduzia o ponto de vista dos autores, inteiramente opposto ao de Lipschütz que, nessa occasião, affirmava a natureza parasitaria das inclusões intranucleares do herpes simples e zoster, considerando-as como Strongyloplasmas. Segundo Luger e Lauda, ao contrario, eram processos puramente degenerativos, embora com caracteres peculiares e bem diversos dos processos nucleares que commummente acompanha'm a necrose e a necrobiose das cellulas.

Offereciam semelhança, senão identidade, a um processo de chromatolyse referido por Heidenhain (1907) em cellulas de diversos tecidos de Triton helveticus. Segundo Heidenhain, os nucleos possuiriam, como constituinte normal, além da basichromatina, caracterisada pela sua affinidade de coloração para com os corantes basicos, uma oxychromatina com affinidade especial para os corantes acidos. $\mathrm{Na}$ chromatolyse de cellulas de diversos tecidos de Triton helveticus e bem assim na degenerescencia oxychromatica das doenças por ultravirus, occorreria augmento notavel da oxychromatina como modificação caracteristica.

Vejamos como é descripta a degenerescencia oxychromatica por Luger e Lauda (1926), os auctores que crearam essa expressão.

As pags. 457 de seu trabalho representam todas as phases evolutivas da degenerescencia oxychromatica, desde uma «initiale Hyperchromatose. Deutliches Hervortreten der Chromatinbälkchen» (Figura $b$ do Abbildung 6), seguida de "Ansammlung kleiner, einfacher oder multipler, homogener (c) oder granulierter (d) oxychromatischer Massen im Zentrum des Kernes», de "Das Oxychromatin hat wesentlich zugenommen, es ist zum Teil homogen, zum Teil granuliert. Das Basichro- 
matin ist aus den zentralen Partien des Kernes zum grossen Teil geschwunden. Kernwandhyperchromatose" (figura $e$ ), de "Abgesehen von geringen Basichromatinmassen ist das ganze Kerninnere mit homogener $(f)$ oder feingranulierter $(g)$ oxychromatischer Innenmasse ausgefüllt», de "Kein Basichromatin im Kerninnern. Kernwandhyperchromatose. Im Kerninnern homogenes ( $h$ und $i$ ) oder granuliertes ( $j$ und $k$ ) Oxychromatin, welches in $i$ und $k$ von der Kernmembran retrahiert erscheint», de "Die entsprechenden Bilder wie bei $h, i, j, k$, bei Aufsplitterung der Kernmembran in einzelne Basichromatinkörner» (figuras $l, m, n, o)$, de "Endstadium; das Basichromatin ist vollständig geschwunden. Der ganze Kern löst sich in eine oxyphile Masse, die in $p$ homogen erscheint, in $r$ noch eine Granulierung erkennen lässt, auf (figs. $p, r) »$.

Vê-se, portanto, pela descripção, e, principalmente, pelas figuras de seu trabalho, que a expressão "degenerescencia oxychromatica», no sentido que lhe dão os seus creadores, comprehende todos os aspectos cvolutivos das inclusões intranucleares das doenças por ultravirus, desde as iniciaes, nas quaes o reticulo de linina e os granulos de chromatina são conservados no nucleoplasma até a phase final, na qual a basichromatina desapparece completamente.

Se assim é, a conclusão a tirar é de que a expressão «degenerescencia oxychromatica» é um' synonymo do termo mais commodo e, hoje, de uso mais generalizado, qual o de «inclusão intranuclear».

Não se justifica, assim, a nosso ver, no estudo das inclusões intranucleares das doenças de virus, uma distincção entre «inclusões intranucleares verdadeiras» $\mathrm{e}$ "degenerescencia oxychromatica», tal como fazem Nicolau, Kopciowska e Mathis (1934) a proposito das inclusões intranucleares da febre amarella.

\section{CONCLUSOES}

1. Em 12 lesões epidermicas colhidas em 8 doentes de alastrim; as cellulas epidermicas apresentam inclusões cytoplasmaticas e intranucleacleares que differem das inclusões correspondentes estudadas, por comparação, ıem uma biopsia de variola vera.

O material de alastrim provem de uma pequena epidemia occorrida em 1932-33 em tropa aquartelada na cidade do Rio de Janeiro, Brasil. A biopsia de variola vera foi praticada durante a grande epidemia observada em 1926, na população civil da mesma cidade. 
2. As inclusões cytoplasmaticas do alastrim não são coloridas pela safranina, quando empregado o methodo de Unna, ao passo que as da variola vera possuem uma nitida safraninophilia.

3. As inclusões cytoplasmaticas do alastrim coram-se em tonalidade que varia do azul ao violeta nos preparados pela hematoxylina-eosina, as da variola vera sendo ordinariamente coloridas em' roseo (acidophilia).

t. Embora a localisação juxta-nuclear seja frequentemente vista nas inclusões cytoplasmaticas do alastrim, o nucleo conserva contornos regulares, não se observando o alojamento das inclusões em depressões de sua superficie, tal como succede, por vezes, com as inclusões cytoplasmaticas da variola vera e da vaccina.

5. As inclusões intranucleares da variola vera apresentam-se, não raro, sob a fórma de corpusculos acidophilos esphericos ou ovoides, solitarios ou multiplos, providos de zonas chromophobas. O nucleoplasma, em sua porção restante, é desprovido de estructura, a memr brana nuclear consideravelmente espessada em virtude da marginação da basichromatina. Esse "aspecto corpuscular» das inclusões intranucleares não foi encontrado no material de alastrim:

6. As inclusões intranucleares do alastrim, quer no homem, quer no Macacus rhesus apresentam um aspecto typico ("aspecto retiforme») representada na figura 22, estampa XXIX de Torres e Teixeira (1934la). e na fig. 44 do presente trabalho): 